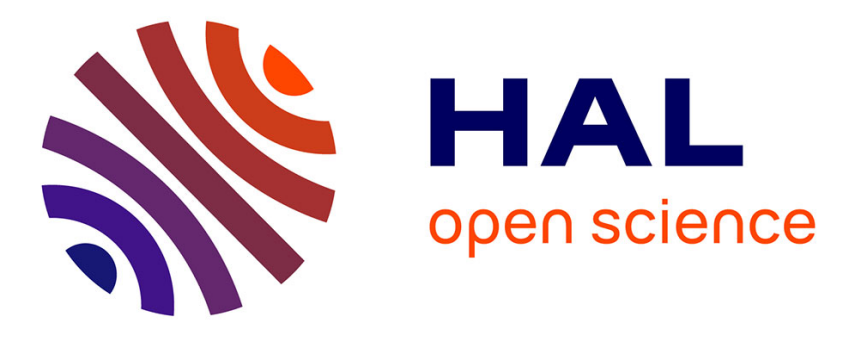

\title{
Improving physical-physiological interaction requirements for maintenance enabling systems specification
}

Romain Lieber, Jean-Marc Dupont, Fabien Bouffaron, Gérard Morel

\section{- To cite this version:}

Romain Lieber, Jean-Marc Dupont, Fabien Bouffaron, Gérard Morel. Improving physicalphysiological interaction requirements for maintenance enabling systems specification. 12th IFAC/IFIP/IFORS/IEA Symposium on Analysis, Design, and Evaluation of Human-Machine Systems, Aug 2013, Las Vegas, United States. pp.CDROM. hal-00859454

\section{HAL Id: hal-00859454 \\ https://hal.science/hal-00859454}

Submitted on 8 Sep 2013

HAL is a multi-disciplinary open access archive for the deposit and dissemination of scientific research documents, whether they are published or not. The documents may come from teaching and research institutions in France or abroad, or from public or private research centers.
L'archive ouverte pluridisciplinaire HAL, est destinée au dépôt et à la diffusion de documents scientifiques de niveau recherche, publiés ou non, émanant des établissements d'enseignement et de recherche français ou étrangers, des laboratoires publics ou privés. 


\title{
Improving physical-physiological interaction requirements for maintenance enabling systems specification
}

\author{
Romain Lieber *, Jean-Marc Dupont **, Fabien Bouffaron *, Gérard Morel * \\ * Nancy Research Centre for Automatic Control (CRAN), Université de Lorraine, CNRS UMR 7039 \\ Campus Science, BP 70239, 54506 Vandoeuvre-lès-Nancy Cedex, France \\ \{romain.lieber, fabien.bouffaron, gerard.morel\}@ univ-lorraine.fr \\ ** So-Innov, 8, rue des Frigos, 75013 Paris \\ jmd@so-innov.fr
}

\begin{abstract}
Recurrent incident reports indicate that ground operators have not always performed the right action or made the right decision following maintenance operations of transport systems. This paper explores first the physical-physiological requirements for a human to perceive right the meaning of symbolic properties technical objects afford when they are being maintained in variable contextualized situations. This paper explores then the impact of these necessary but not sufficient Human Factors requirements on the specification process of a maintenance enabling system by prototyping a door latch^lock case-study with a modeling environment based on SysML.
\end{abstract}

Keywords: Model-Based Systems Engineering, Human Factors Requirements, Human-Machine Interaction, Sysml

\section{INTRODUCTION}

Recent papers exhibit the necessary evolution of current systems engineering framework in the aim of taking into account all the critical interactions of a socio-technical system since the specification phase (Ruault et al., 2012). By doing so, the objective is to ensure system behavior is kept within an accepted domain of performances whatever is the context of use. Those performances depend on the synergies of the different interactions that take place between technical and human systems when operating a common object. For example, they can rely on the homomorphic correspondence between the behavior of the physical processes to be controlled and the corresponding control mental schemes that operators can have through human-machine interfaces (Galara, 2006).

Human Factors consideration in Systems Engineering also known as Human Systems Integration (Booher, 2003) implies to start working on the overall positive performance (Wolff et al., 2012) of all the interfaces of a socio-technical system (human-machine, human-human and system-environment) and not on the ways of avoiding human errors.

These different interfaces exhibit emerging complex interactions. Some of them are inquired to ease the whole system performances and facilitate system resilience capabilities within disruptive unanticipated environment. Other ones are designed to finalize the system mission according to the purpose of its context of use.

The paradigm we have explored in our work is based on the hypothesis of possible inter-operations between physiological and technical processes for human-machine modeling. This article focuses more precisely on the specification of a physical-physiological perception interaction within a ModelBased Systems Engineering (MBSE) approach of a maintenance enabling system (Pyster et al., 2012).

\section{PHYSICAL-PHYSIOLOGICAL CONTEXTUALIZED- INTERACTION PROBLEM-STATEMENT}

Technical objects exhibit physical properties that can afford symbolic properties for human operators aiming to act within contextualized situations. Although these ground operators have been trained to capture the meaning of these affordances, recurrent reports within the area of transport systems indicate that incidents are not always clearly related to the technical or the human object but rather to the interaction between both.

Typical maintenance related-incidents are linked to equipment doors which remain unlatched but closed after maintenance task completion prior to walk around inspections.

\subsection{Latch $\wedge$ Lock state-control issues}

Door closing is currently ensured by a technical mechanism $\mathrm{M}_{\mathrm{LL}}$ composed of two independent and distinct means called Latch and Lock. The aim of the first one is to maintain the doors in a closed position. The aim of the second one is to ensure the doors are locked. In return, this mandatory functional and physical independency of two technical means induces human decision-making issues to ensure the Latch $\wedge$ Lock state of equipment doors. 
Operators are both power-sources and perception-sinks to manipulate various mechanisms for example getting access to equipment that is located behind the door and has to be replaced. Standard manipulation actions and their related perceptions are well specified and follow an 'antinomic logic' according to a Latch-Lock Procedure $\mathrm{P}_{\mathrm{LL}}$ (Fig. 1).

The objective of such a structured sequence of actions is to ensure the reinstating of the operational requirements linked to the door Latch $\wedge$ Lock state (noted $\mathrm{R}_{\mathrm{LL}}$, Table 1). The different operators (Maintenance Technician_TEA, Team Leader_CE, Maintenance Head_CMO) that use $\mathrm{M}_{\mathrm{LL}}$ participate to this requirement satisfaction by controlling latch alignment with the surface of the doors: Latch has to be level with the surface of the doors (noted $A_{L L}$, Table 1).

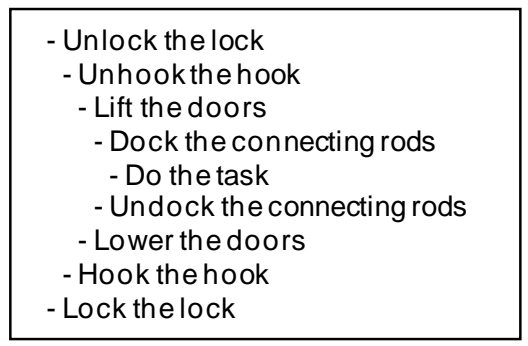

Fig. 1. Latch $\wedge$ Lock $P_{\text {LL }}$ procedure

The Latch $\wedge$ Lock mechanism affords a lot of interaction possibilities so that it can be controlled in terms of alignment. More precisely, $\mathrm{M}_{\mathrm{LL}}$ can be considered as a source of potential sensory signals that are perceived by the operators considering their physiological perceptive thresholds.

Each mechanism signal is a physical quantity that propagates through space and time to reach each human operator in order to trigger an action that is stored in the form of a learnt knowledge somewhere in his brain.

Regarding our operational control system function, operators can be stimulated by three types of signals:

- Visual signal: by a visual inspection requiring a certain position of the operator (on his knees, lying down on the ground, different head positions), he could see if $M_{L L}$ position is level with the door

- Tactile signal: by touching the surface of the door, operator could feel with his hand if $\mathrm{M}_{\mathrm{LL}}$ is level with the door.

- Sound signal: when manipulating $\mathrm{M}_{\mathrm{LL}}$ for closing the door an acoustic signal as the click of a hook could help him to deduce the correctness of the alignment.

Those interaction possibilities are constrained by the different operational environment characteristics. Maintenance operations can be realized outside or inside a shed with either natural or artificial lighting and in a quiet or noisy environment.

All that question us about the physical-physiological nature of the human-machine perceptive interaction in order to communicate symbolic properties exhibited by $\mathrm{M}_{\mathrm{LL}}$.

Original equipment manufacturers as well as equipment customers correct some operational issues related to the use by human operators of $\mathrm{M}_{\mathrm{LL}}$ all along its life cycle.
Mechanism has been improved and the side of the latch has been painted with an orange color. As a consequence, a new operational requirement $\mathrm{REC}_{\mathrm{LL}}$ was issued (Table 1). This requirement has to be fulfilled before operating the equipment and is added to the control system function.

\begin{tabular}{|l|l|}
\hline $\mathrm{R}_{\mathrm{LL}}$ & $\begin{array}{l}\text { «Operational Requirement» } \\
\text { Make sure that the doors are fully latched when } \\
\text { closed }\end{array}$ \\
\hline $\mathrm{A}_{\mathrm{LL}}$ & $\begin{array}{l}\text { «Operational Requirement» } \\
\text { Make sure that all latch handles stay in the } \\
\text { doors slots and are aligned with the equipment } \\
\text { adjacent surface }\end{array}$ \\
\hline $\mathrm{REC}_{\mathrm{LL}}$ & $\begin{array}{l}\text { «Operational Requirement» } \\
\text { Proceed to a visual inspection of all parts easily } \\
\text { visible of the latches after each manipulation } \\
\text { and correct any abnormality before operating } \\
\text { the equipment }\end{array}$ \\
\hline
\end{tabular}

Table 1: Examples of Operational Requirements for controlling an access door Latched-Locked state

\subsection{Latch $\wedge$ Lock state-control by orange visual signal}

The orange color is conventionally a visual alert signal triggering a particular attention in maintenance operation context, meaning in our case-study that the door is not well locked but nevertheless maybe closed.

On the technical hand, orange color represents a property of the light characterized by a given wavelength that is a physical scale corresponding to a quantity of photons (Fig. 2 ). On the human hand, orange color is captured by specific cells called cone (a type of photoreceptors) located on the very small part of the retina called fovea (a cellular mosaic).

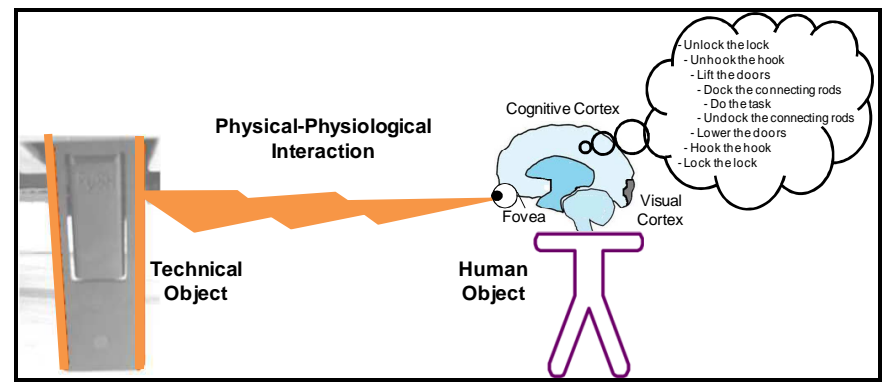

Fig. 2. Visual Physical-physiological interaction between the Technical-Object $\left(\mathrm{M}_{\mathrm{LL}}\right)$ and the Human-Object (i.e. visual perceptive system composed of the eye-fovea and the visual cortex)

Thus, that questions us about the transmitted flow (from the Latch up to the Fovea) requested to stimulate the related visual cortex.

\subsection{Discussion}

We have pointed out the important impact of the maintenance context on operational performances for a human to perceive right the meaning of symbolic properties afforded by 
technical objects. This overall consideration focuses our attention on the physical-physiological communication upstream the symbolic communication between artifact and human (Gibson, 1975). So, we first investigate on a modeling framework that allows us to well understand this perceptive process in order to specify physiological requirements on our specific maintenance enabling system case-study.

\section{PHYSICAL-PHYSIOLOGICAL MODELING ISSUES}

INTERACTION

We assume that by focusing on the understanding of the physical-physiological interaction nature we can success in the objective of specifying measurable requirements that meet MBSE needs. This understanding is based on both specific works related to perception and action physiology (Berthoz, 2012) and more general ones related to Integrative Physiology (Chauvet, 1993).

\subsection{Physical-Physiological Interaction Modeling Framework}

Our rationale of selecting the Mathematical Theory of Integrative Physiology (MTIP) is linked to the functional representation of a living system that its related framework supports through a physiological process-based modeling.

These physiological processes are hierarchically organized within space and time scales and stimulated by a set of functional interactions $\psi_{\mathrm{LL}}$ that spread over structural discontinuities (Fig. 3). Such discontinuities modify the nature of $\psi_{\mathrm{LL}}$ that is of importance when transmitting a physical flow to a physiological environment.

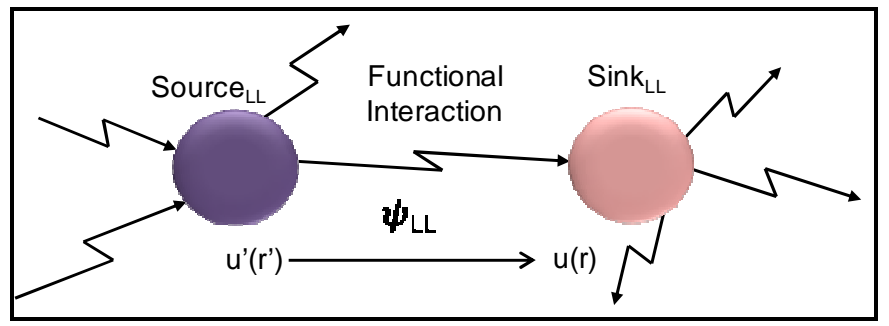

Fig. 3. Perceptive Functional Interaction $\psi_{\mathrm{LL}}$ between a Source $_{\text {LatchLock }}$ (visual signal) located in r' and a Sink LatchLock (the fovea) located in $r$

This interaction $\psi_{\mathrm{LL}}$ can be seen also as a trigger of many mental processes that lead to the realization of the Latch $\wedge$ Lock actions thanks to the corresponding knowledge (noted $\mathrm{K}_{\mathrm{LL}}$ ) stored in the 'cognitive cortex'.

Summarizing this functional organization understanding lead us to consider each physiological process involved in this 'perception-cognition loop' as a kind of thyristor in order to highlight the importance of the right stimuli to propagate $\psi_{\mathrm{LL}}$ (Fig. 4). Specially the first physical-physiological one emitted by the technical object.

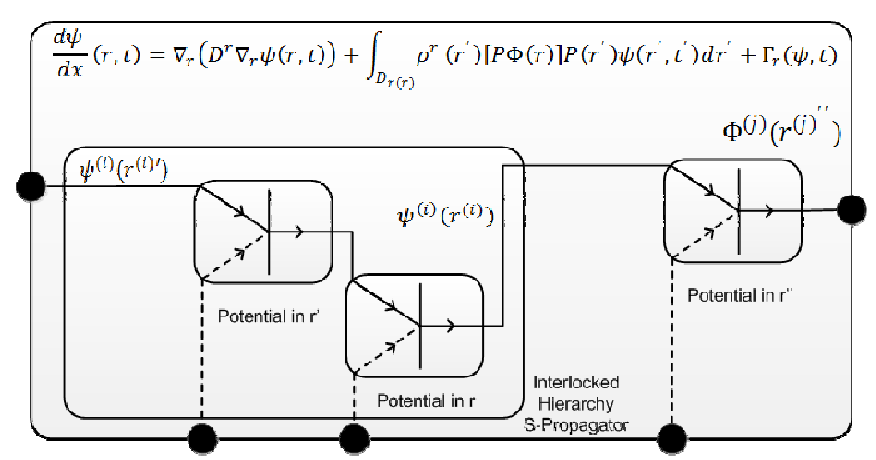

Fig. 4. Process-based modeling of the physical-physiological interaction $\psi_{\mathrm{LL}}$ spreading over r' and r' space locations and stimulating a cognitive interaction

Finally, as addressed by field equations in (Fig. 4), the MTIP mathematical foundations aim to simulate those physicalphysiological processes with computational software tools, including the dedicated PhysioMatica ${ }^{1}$ one. This aspect is important within a collaborative MBSE process, as we need to progress in the phenomenon-of-interest understanding through simulations and hypothesis.

However, the difficulties we have to face when applying the MTIP mathematical representation are the availability of the physiological and anatomical data at the required level of details such as densities of connectivity. Thus, we focus on the propagation of $\psi_{\mathrm{LL}}$ from the latch to the fovea assuming from MTIP the different structural discontinuities of the eye introduce no modifications of the nature of the flow of photons (i.e. robust organ).

\subsection{Visual-Perception Physical-Physiological Requirements}

This hypothesis enables us to consider current available physiological data for this specific area in order to specify the law $K_{\mathrm{LL2} 2.2}$ at a scale-factor sufficient for a MBSE specification phase. The spreading of the stored knowledge $\mathrm{K}_{\mathrm{LL}}$ is then dictated by this amount of electrical power coming from the transmutation of the "orange color photon quantity' received by the Fovea. This quantity depends directly on the reflected one from latch according to the law $\mathrm{M}_{\mathrm{LL} 2}$ (Fig. 5).

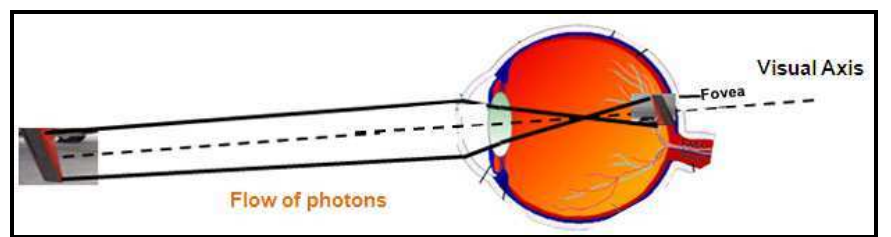

Fig. 5. A Technical Source located in the physical environment interacts with a Physiological Source (i.e. eye or $\mathrm{H}_{\mathrm{LL}}$ ) located in the physiological environment through the spreading of photons characterizing the orange color.

The luminance of a light source is a photometric measure of light intensity that is dependent on the human eye sensibility.

\footnotetext{
${ }^{1}$ http://www.vfs-bio.eu/
} 
Color can be perceived if cone perceptive threshold (beyond $10-3 \mathrm{~cd} / \mathrm{m} 2$ ) is reached (Purves et al., 2011). The corresponding physical light power in watt should be evaluated following to the wavelength of the photons. Thus, for a wavelength equal to $610 \mathrm{~nm}$ (medium orange), the surface of the fovea should receive 6.10 power 5 photons /s.

That leads to some qualitative and quantitative physicalphysiological requirements addressed in Table 2.

\begin{tabular}{|c|c|}
\hline$\underline{\text { ID }}$ & DESCRIPTION \\
\hline \multirow[b]{2}{*}{$\mathrm{K}_{\mathrm{LL} 2}$} & «Physiological Requirement» \\
\hline & $\begin{array}{l}\text { The Visual-Sink } \text { LL }_{\text {must }} \text { be aligned on the } \\
\text { Signal-Source }_{\mathrm{LL}}\end{array}$ \\
\hline & «Physiological Requirement» \\
\hline $\mathrm{K}_{\mathrm{LL} 2.1}$ & $\begin{array}{l}\text { The anthropometric axes must be aligned } \\
\text { according to the visual axis }\end{array}$ \\
\hline $\mathrm{K}_{\mathrm{LL} 2.2}$ & $\begin{array}{l}\text { «Physiological Requirement» } \\
\text { The photons flow received by the fovea must be } \\
\text { specified according to the law : } \\
\text { nb } \lambda=2.10-13 /(\mathrm{h} v)=6.10^{5}(\mathrm{~s}-1)\end{array}$ \\
\hline $\mathrm{M}_{\mathrm{LL} 2}$ & $\begin{array}{l}\text { «Technical Requirement» } \\
\text { The reflectance coefficient } \rho \text { determines the } \\
\text { fraction of the reflected power Po versus the } \\
\text { received power Pi according to : } \\
\qquad P_{0}(x, t)=\rho P_{i}(x, t)\end{array}$ \\
\hline $\mathrm{M}_{\mathrm{LL} 2.3}$ & $\begin{array}{l}\text { «Technical Requirement» } \\
\text { The latch must be aligned on the visual } \\
\text { axis according to the transformation } \\
\text { matrix: } \\
\qquad Z_{O}={ }^{\circ} T_{V} Z_{V}\end{array}$ \\
\hline
\end{tabular}

Table 2. A collection of Physical-Physiological Interaction Requirements that we have highlighted during our study

Note that the alignment requirement $\mathrm{K}_{\mathrm{LL} 2}$ impacts others human factors such as $\mathrm{K}_{\mathrm{LL} 2.1}$ related to the operator posture and technical factors such as $\mathrm{M}_{\mathrm{LL2.3}}$ related to the latch position.

\subsection{Discussion}

A MTIP-based modeling enables to functionally understand the physiological behavior of a human being in order to make hypothesis for computational simulation purposes according to available data and the scale-factor related to the MBSE decision-making process. This measurability requirement has limited our case-study to the specification of the physicalphysiological orange-signal perception.

The same approach could be applied to the two others sensory signals: tactile and sound. Thus, the physicalphysiological requirement analysis would focus on the interactions between the $\mathrm{M}_{\mathrm{LL}_{-}}$Source and respectively skinmechanoreceptors_Sink and ear-hair cells_Sink. Touching the surface of the door corresponds to the propagation of a pressure wave from the receptors to a cortical region called thalamus only if the received stimulus reaches the expected threshold to trigger it. Hearing the click of the hook follows the same structure.

\section{PHYSICAL-PHYSIOLOGICAL} SPECIFICATION-PROCESS ISSUES

The physical-physiological interaction is one of the interactions which shall be formalized as Human Factors requirements (red dotted arrows) during maintenance system specification process (Fig. 6). Maintenance system can be defined as the set of products that support the target system into its mission completion.

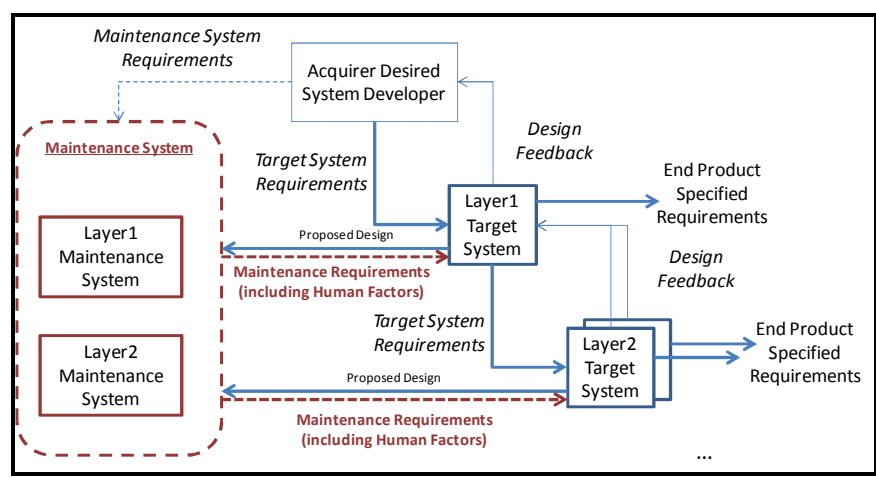

Fig. 6. Top-down development for target and maintenance systems highlighting the contribution of maintenance operations requirements into target system definition (based on EIA-632)

This informal specification of technical-human interactions within MBSE process is first formalized according to the Requirements analysis model for socio-technical systems developed by (Hall et al., 2005) in order to outline then the interest of a co-specification process.

\subsection{Physical-Physiological Interaction Modeling Framework}

Hall's reference model (Fig. 7) that is based on Jackson's 'Problem Frames' approach (Jackson, 1995) defines several modeling artifacts that are distributed among the environment domain (red circle) and the socio-technical system domains (green and blue circles).

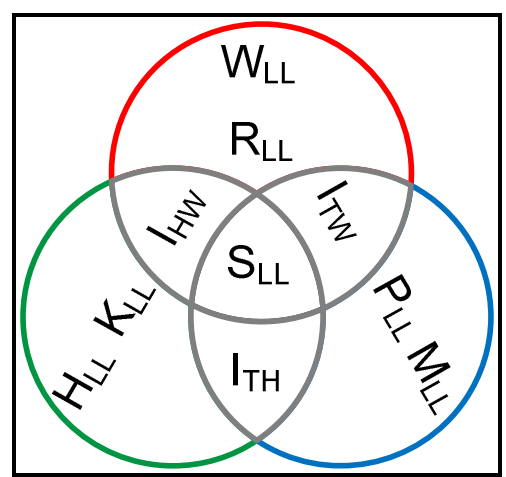

Fig. 7. The requirements analysis model for socio-technical systems

Those artifacts enable us to formalize the predicate satisfying $\mathrm{R}_{\mathrm{LL}}$ in order to specify a socio-technical target system $\mathrm{S}_{\mathrm{LL}}$ :

$$
\mathrm{W}_{\mathrm{LL}} \wedge \mathrm{I}_{\mathrm{TW}} \wedge \mathrm{I}_{\mathrm{HW}} \wedge \mathrm{I}_{\mathrm{TH}} \Rightarrow \mathrm{R}_{\mathrm{LL}}
$$


Thus, the predicate (1) highlights the fact that at least three types of interaction specifications $\left(\mathrm{I}_{\mathrm{TW}}, \mathrm{I}_{\mathrm{HW}}, \mathrm{I}_{\mathrm{TH}}\right.$ ) enable to specify concurrently the target system $\mathrm{S}_{\mathrm{LL}}$ (grey part) according to $\mathrm{I}_{\mathrm{TW}} \wedge \mathrm{I}_{\mathrm{HW}} \wedge \mathrm{I}_{\mathrm{TH}} \Rightarrow \mathrm{S}_{\mathrm{LL}}$.

More precisely,

- $\mathrm{W}_{\mathrm{LL}}$ corresponds to the world knowledge that describes the relevant equipment operational environment and states the requirements $R_{L L}$.

- $\mathrm{I}_{\mathrm{TW}}$ specifies the target system technical requirements prescribing the Latch-Lock Procedure $\mathrm{P}_{\mathrm{LL}}$ that implements the Latch-Lock mechanism $\mathrm{M}_{\mathrm{LL}}$ within $\mathrm{W}_{\mathrm{LL}}$ according to: $\mathrm{W}_{\mathrm{LL}} \wedge \mathrm{M}_{\mathrm{LL}} \wedge \mathrm{P}_{\mathrm{LL}} \Rightarrow \mathrm{I}_{\mathrm{TW}}$.

- $\mathrm{I}_{\mathrm{HW}}$ specifies the target system human factors requirements prescribing the capabilities $\mathrm{K}_{\mathrm{LL}}$ that the maintainer $\mathrm{H}_{\mathrm{LL}}$ has to own to operate within $\mathrm{W}_{\mathrm{LL}}$ according to: $\mathrm{W}_{\mathrm{LL}} \wedge \mathrm{H}_{\mathrm{LL}} \wedge \mathrm{K}_{\mathrm{LL}}$ $\Rightarrow \mathrm{I}_{\mathrm{HW}}$.

- $\mathrm{I}_{\mathrm{TH}}$ specifies the target system human-machine interaction requirements prescribing the requested interface properties within $\mathrm{W}_{\mathrm{LL}}$ according to: $\mathrm{W}_{\mathrm{LL}} \wedge \mathrm{K}_{\mathrm{LL}} \wedge \mathrm{P}_{\mathrm{LL}} \Rightarrow \mathrm{I}_{\mathrm{TH}}$.

Our studied physical-physiological interaction specification describes one type of the human-machine interaction specification $\mathrm{I}_{\mathrm{TH}}$ that can impact the considered target system design. It's the result of a set of transformations during requirement analysis process (Bouffaron et al., 2012) and can be seen as a sub-assembly of $\mathrm{S}_{\mathrm{LL}}$ that satisfies $\mathrm{R}_{\mathrm{LL}}$ within $\mathrm{W}_{\mathrm{LL}}$.

4.2. Physical-Physiological Interaction-based Maintenance System Co-Specification Process

The specification of the system as a whole $S_{L L}$ leads us to consider it as a set of functions (satisfying $\mathrm{R}_{\mathrm{LL}}$ ) at the MBSE architectural functional phase. Among these functions, we focus on the perception one.

The transition to the MBSE architectural organic phase leads us to consider this function allocation on both technical and human components. To do so, the related two domains have to collaborate to specify the perception interactions as a whole. The difficulty raised by MTIP is to retro-allocate a functional view from the human organic one in order to facilitate the functional architecting of the whole system $\mathrm{S}_{\mathrm{LL}}$. As a consequence in a MBSE context, we highlight the need of two new roles within the systems engineering domain: the Technical and Human Factors Architects in order to better balance the allocation of functions to organic components respectively technical or human based. In other words, it means that system, technical and human factors architects have to share a common functional representation of the target system as a whole.

Generally speaking, the system specification process (Fig. 8) can be seen as a series of transformations between iterative problem-space_Source and solution-space_Sink within different domains. A problem-space describes requirements that solution-spaces have to satisfy by prescribing requirements based on domain skills. As example, $\mathrm{K}_{\mathrm{LL} 2.1}$ and $\mathrm{M}_{\mathrm{LL2.3}}$ share a common alignment requirement on the visual axis.

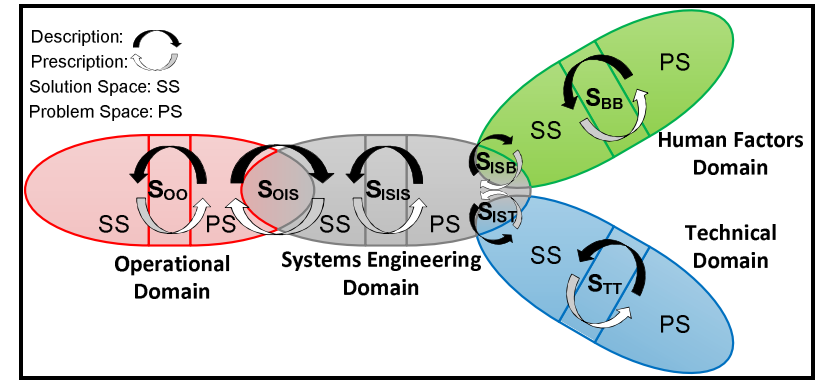

Fig. 8. Systems engineering, pivotal domain between two expert domains respectively Technical and Human

\subsection{Discussion}

This vision of functionally defining a system as a whole prior to architecting it with two kinds of organic components \{Human and Technical\} is not widely shared in current systems engineering organization. Indeed, Human considerations are seen as extra-burden within the teams that don't know how to deal with too often non-measurable requirements.

By proposing such a rationalized specification process that focuses on the physical-physiological nature of the interaction we aim to improve the current situation and insist on the necessary collaborative work (under System Architect responsibility) between Human and Technical domains to obtain measurable human-machine requirements that satisfy stakeholders' operational requirements.

\section{PHYSICAL-PHYSIOLOGICAL INTERACTION SPECIFICATION-VERIFICATION ISSUES}

The Systems Modeling Language (SysML) is the de-facto candidate that can facilitate the collaboration between the four domains in (Fig. 8) as it's defined as "a general-purpose modeling language for systems engineering" (OMG, 2012).

Our computational framework to specify measurable physical-physiological requirements reinforces this collaborative process by facilitating co-prototyping.

\subsection{SysML-Based Verification Mock-Up}

The below scenario (Fig. 9) describes plausible contexts of maintenance with several operators and complementary roles (Operator_CMO, Operator_CE, Operator_TEA) in order to satisfy the operational requirement $\mathrm{R}_{\mathrm{LL}}$. This scenario illustrates the interoperation between target system models. Those models are used to specify physical-physiological interaction requirements of the alignment that meet the operational recommendation $\mathrm{REC}_{\mathrm{LL}}$. The related mock-up articulates our system specification process with the "SysML-Harmony ${ }^{2}$ » process so that the functional analysis of the target system can be checked by model execution.

\footnotetext{
${ }^{2}$ Based on the tool independent IBM $®$ Rational ${ }^{\circledR}$ Rhapsody ${ }^{\circledR}$, the process harmony provides systems engineers with a step by step guide on using the SysML
} 
Such interactions are initially specified through services describing the result of the visual perception. For our case study, there are two types of results: "Orange signal perceived" or "Orange signal not perceived".

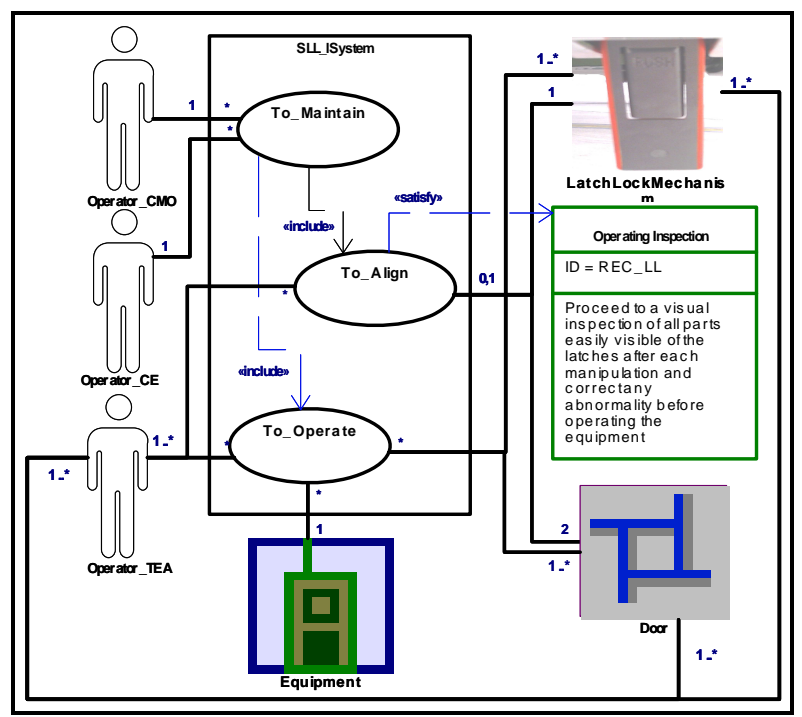

Fig. 9. Use case diagram of the target system

This specification is not sufficient to properly formalize the requirements of the interfaces considered as the starting point of the different contextualized interactions. Based on MTIP framework, the human factors domain-of-interest (physiology) prescribes to system engineering domain a set of measurable requirements $\left\{K_{L L 2}, K_{L L 2.1}, K_{L L 2.2}\right\}$ to be satisfied in order to meet $\mathrm{REC}_{\mathrm{LL}}$. These requirements can be formalized through a parametric diagram (Fig. 10) in the form of constraint.

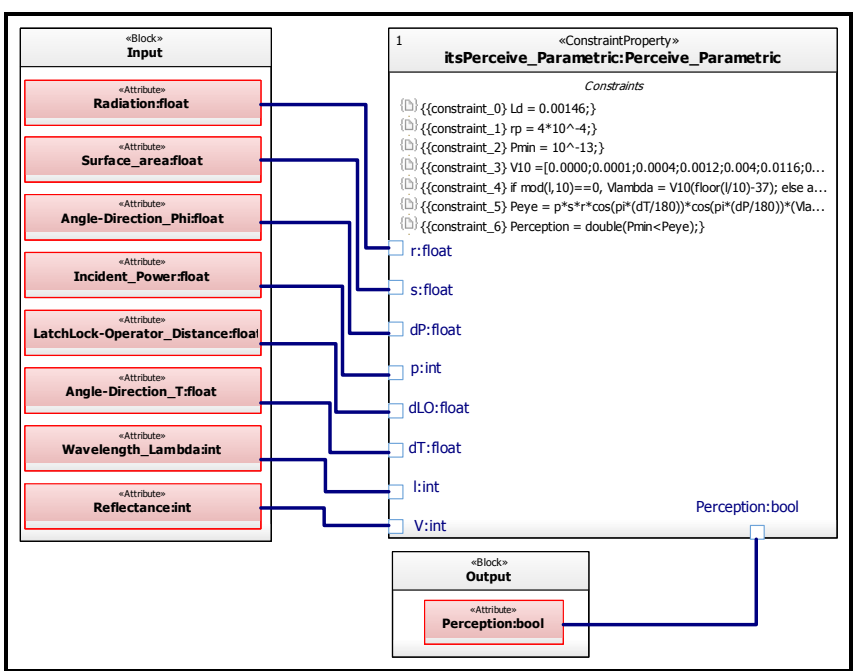

Fig. 10. Parametric diagram describing the physicalphysiological interaction of visual perception

SysML parametric diagrams provide a way to integrate engineering analysis models described in mathematical equations constraints. Thus we have the capabilities of simulating several scenarios of light rendering in order to determine the appropriate physiological lighting efficiency requested to perceive or not an orange visual signal (Fig. 11).

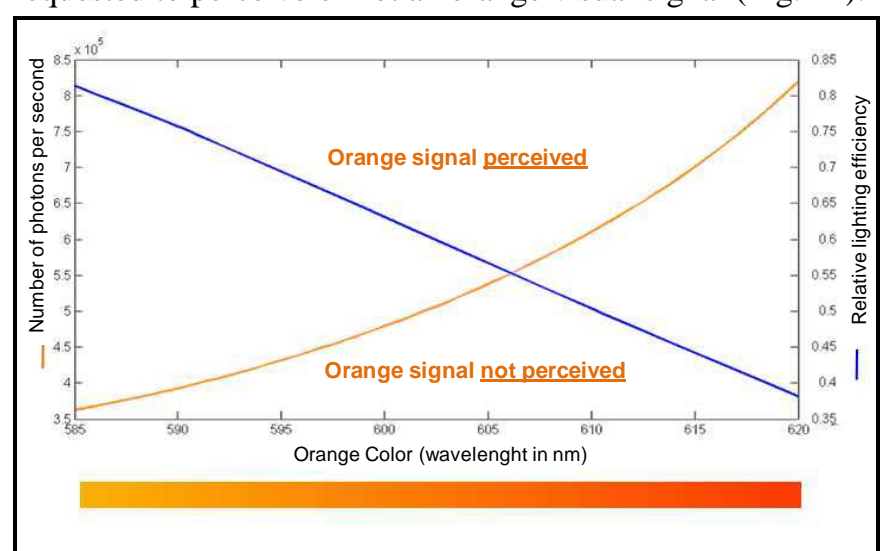

Fig. 11. Result of a physical-physiological interaction simulation using the computer algebra system Matlab ${ }^{\circledR}$

This lighting efficiency depends on several parameters: the selected orange color (see range of wavelength below), object's material, location or distance of the interacting objects. This evaluation allows us to verify the satisfaction of the set of measurable requirements $\left\{K_{L L 2}, K_{L L 2.1}, K_{L L 2.2}\right\}$.

The functional specification of a physical-physiological system as a whole is structurally represented by an internal bloc diagram (Fig. 12).

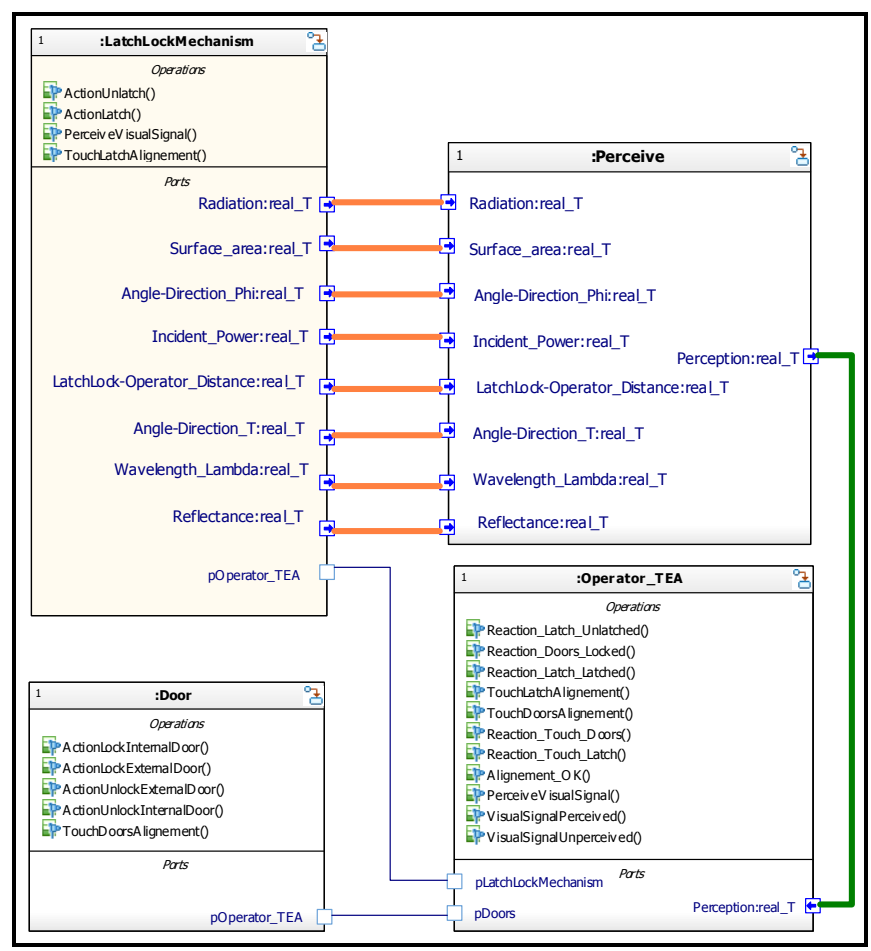

Fig. 12. Internal Bloc Diagram with «Simulink $® »$ block specifying the use case "To Align"

The object "Part Perceive" is an instance block of type "Simulink" which describes the behavior of the visual perception interaction based on the description provided by human factors domain. 
IBM® Rational® Rhapsody® enables model execution by code generation of operators and technical objects behaviors captured in Statecharts and visual perception interaction captured in "Simulink" part. Executing different operational scenarios in the context of maintenance allows us to verify the satisfaction of the requirement $\mathrm{REC}_{\mathrm{LL}}$.

\subsection{Discussion}

Our work underlines the interest of co-simulations between Systems Engineering and expert domains in order to perform verification and validation of heterogeneous system described by multi-language models (e.g. SysML, Simulink, Modelica, etc.) throughout the design development process (Fig.13).

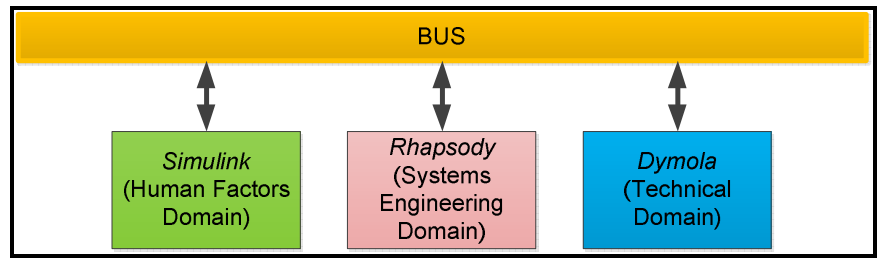

Fig. 13. Bus of co-simulation between the different engineering domains concerned by Human-Machine System specification

One of the interests of the co-simulation is that experts from various domains can use their own tools (from their respective domains) to interoperate with each other and thus verify and validate the system specification as a whole. Recent works aim to implement a co-simulation bus between Simulink and Rhapsody to specify the physical-physiological interaction of visual perception. It can be achieved by dedicated tools ${ }^{3}$ enabling co-simulation of different heterogeneous models with the SysML-based model of the system under specification. Thereafter we can consider connecting other models such as a model of the Latch $\wedge$ Lock technical system with this co-simulation bus.

Such a possibility will have to be widely deployed among critical human-machine system engineering as it represents a promising way-of-working to better anticipate system performances and master its development. Besides it supports the Systems Engineering 2020 Vision of the INCOSE (INCOSE, 2007). Improving system process-based modeling by focusing on the functional and organic nature of all system interactions will be one of the major challenges.

\section{CONCLUSIONS AND FUTURE WORK}

We have presented in this paper some of the results (Morel et al., 2013) that we have obtained in the context of a multidisciplinary team composed of physics and physiology experts placed into a collaborative MBSE environment. We only focused on a physical-physiological perception interaction $\mathrm{I}_{\mathrm{TH}}$ of a human-machine system. Regarding this system function, we underlined that the cognition function

\footnotetext{
${ }^{3}$ http://www.chiastek.com/
}

shall be stimulated by an appropriate physical-physiological flow if we want to obtain the expected operator action. This brought the attention on the physical communication prior to the symbolic communication traditionally covered by Affordance-Based Human-Machine Approach (Norman, 2004).

We tried to demonstrate that having human factors measurable requirements enable to put all specification process stakeholders into a functional continuum. Although, a full MTIP-based modeling requests a lot of physiological data that are missing at this time, its foundations are already efficient for human-functional understanding.

To success in better improving the specification of a maintenance system, some pre-requisites shall be met: make a change within traditional systems engineering organization, have the appropriate modeling framework and select the critical system functions to be examined.

\section{REFERENCES}

Berthoz, A. (2012). Bases neurales de la décision. Une approche de neurosciences cognitives. Annales Médicopsychologiques, 170(2), pp. 115-119, (in French).

Booher, H.R. (2003). Handbook of Human Systems Integration. Wiley, Hoboken.

Bouffaron, F., Gouyon, D., Dobre, D., Morel, G. (2012). Revisiting the interoperation relationships between systems engineering collaborative processes. 14th IFACINCOM'2012 Symposium. Bucarest, Roumanie.

Chauvet, G. (1993). Hierarhical functional organization of formal biological systems: a dynamical approach, I to III. Philosophical Transaction of the Royal Society London, pp.425-481.

EIA-632. (1999). GEIA Standard processes for engineering a System.

Galara, D. (2006). Roadmap to master the complexity of process operation to help operators improve safety, productivity and reduce environmental impact. Annual Reviews in Control, №30, pp.215-222.

Gibson, J. (1977). The Theory of Affordances. Robert Shaw \& John Bransford (réds), Perceiving, Acting, and Knowing.

Hall, J., Rapanotti, L. (2005). Problem Frames for SocioTechnical Systems. A. Silva \& J. L. Maté (Éds.), Requirements Engineering for Socio-Technical Systems, pp.318-339.

INCOSE. (2007). Systems Engineering Vision 2020, v2.03. International Council of Systems Engineering.

Jackson, M. (1995). Deriving specifications from requirements: an example. Proceedings of the 17th International Conference on Software Engineering, pp.15-24.

Jackson, M. (1997). The meaning of requirements. Annals of 
Software Engineering, 3 (1), pp.5-21.

Morel,G., Dupont, J-M., Lieber, R., Bouffaron, Mery, D., F., Mayer, F., Marty, J-L. (2013). Spécification d'exigences physico-physiologiques d'interaction homme-machine en ingénierie système. Génie Logiciel, $\mathrm{N}^{\circ} 104$, (in French).

Norman, D. (2004). Affordance, Conventions and Design (Part 2). Note in Don Norman's jnd.org website, human-centered design.

OMG. (2012). OMG Systems Modeling Language (OMG SysML) (v 1.3).

Purves D., Augustine G. J., Fitzpatrick D., Hall W. C., LaMantia A.-S., White L. E. (2011). Neuroscience (Fifth Edition), Sinauer Associates, Inc.

Pyster, A., D. Olwell, N. Hutchison, S. Enck, J. Anthony, D. Henry, and A. Squires. 2012. Guide to the Systems Engineering Body of Knowledge (SEBoK) version 1.0.1. Hoboken, NJ: The Trustees of the Stevens Institute of Technology @2012. Available at: http://www.sebokwiki.org.

Ruault, J-R., Vanderhaegen, F., Luzeaux, D. (2012). Sociotechnical systems resilience. Proceedings 22nd Annual INCOSE International Symposium. Rome, Italy.

Wolff, M., Mollard, R. (2012). Prise en compte des facteurs humains dans les processus d'ingénierie système: Quelles tendances pour le futur? Génie logiciel, $\mathrm{N}^{\circ} 100$, pp.22-27 (in french). 